\title{
The application studies of a new fuzzy-adaptive PID control tecnology in the electrol-hydraulic proportional valve controller
}

\author{
Shushang Zhao ${ }^{1, a}$, Lixia Yin ${ }^{2, b}$ and Yahui Zhang ${ }^{3, c}$ \\ ${ }^{1,2,3}$ School of Mechatronics Engineering, Henan University of Science and Technology, \\ Luoyang, China \\ asszhao@vip.sina.com, ${ }^{b}$ lixiazhiyin@163.com, 'czyh_haust@163.com
}

Keywords: Fuzzy control; Self-adjustment factor; Integral separated PID; Simulink simulation

\begin{abstract}
For the lack of the fuzzy self-adaptive PID controller which applied in the industrial process control, a new kind of fuzzy self-adaptive PID controller was introduced. Fuzzy Control part will have the ability to automatically adjust the control rules by plusing a fuzzy self-adjustment factor based on the original fuzzy self-adaptive control system. And PID part adopts integral separated PID control.Then, the control system will have a stronger accommodation, satisfactory control effect is equally provided for different control object.Based on the simulation contrast of the traditional fuzzy self-adaptive PID controller and the fuzzy adaptive PID controller with self-adjustment factor introduced in this paper to show that, the new intelligent controller has a better control effect and robustness. Good control effect is got by simulation when it used for electro-hydraulic control system of proportional valve.
\end{abstract}

\section{Introduction}

Fuzzy self-adaptive PID controller has been widely used in the industrial control and a good control effect has been received. But the numerical size of quantification factor $K e$ (input variables error) and $\mathrm{Kec}$ (error rate) from conventional fuzzy control rules has a great impact on system performance[1].And fuzzy control rules once determined, the quantification factors will determine down.thus, the control effect of the controller will be limited. The control rules could be flexibly adjusted by transforming the self-adjustment factor if we increase self-adjustment factor based on fuzzy PID controller for fuzzy control part. That is, quantitative factor of the fuzzy PID controller can be changed along with the changes of control system operation, and the performance of the system will be further improved.So this paper will focus on the analysis of the method to realize fuzzy PID controller with self-adjustment factor, which is applied to the electro-hydraulic proportional valve control system.

\section{Fuzzy PID controller with self-adjustment factor}

When the domain level of input variable $e$ and $e c$ and output control quantity of $u$ are devided the same, for a two-dimensional fuzzy controller, the query table of fuzzy control often use the following way to reasoning:

$$
u \approx-(e+e c) / 2
$$

If we add an adjustment factor $\beta$ on the basis of the above formula, namely:

$$
u \approx-[\beta e+(1-\beta) e c] / 2 \quad \beta \in(0,1)
$$

$\beta$ is the adjustment factor, called weighted factor too.A different weighted degree of erro and erro rate can be changed by adjusting the size of $\beta$, thereby adjusting fuzzy control rules [2].The weighted value of the erro should be bigger than the erro rate when the error is large, as soon as possible to reduce the system error; On the contrary, the weighted value of the erro rate should be bigger than the erro when the error is small. Namely, strengthen the control of the error rate to avoid big overshoot. However, the problems from troditional fuzzy self-adaptive controller can not be avoided once the 
weighted factor is determined. Therefore, a kind of fuzzy controller with aself-adjustment factor as the fuzzy contol part of the new intelligent controller is designed in this paper. To realise self-ajustment of the fuzzy control, different weighted factor will be introduced in different erro level.

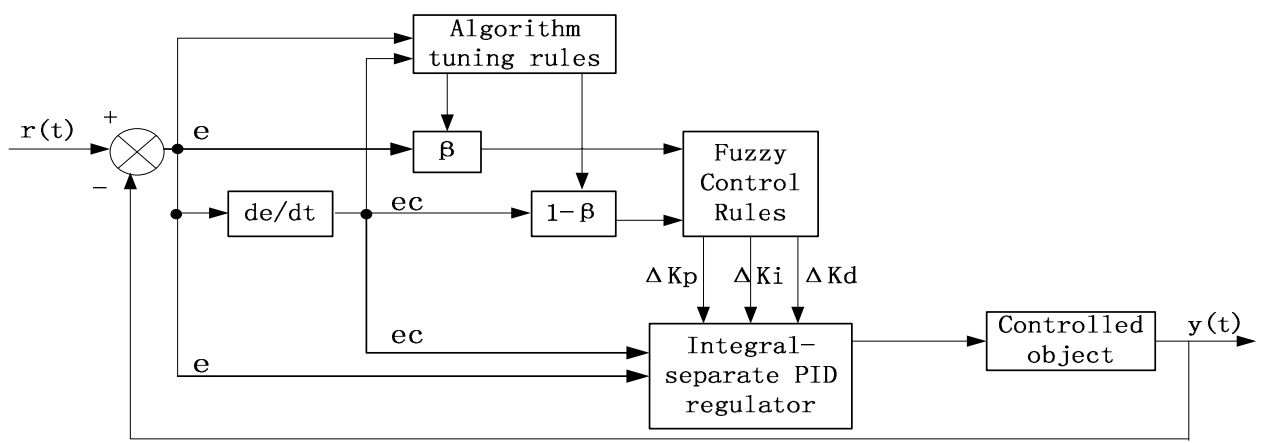

Fig.1, System schematics of Fuzzy PID controller with self-adjustment factor

Design Principles: Since the self-adjustment factor $\beta$ is produced by fuzzy reasonning, therefore, equivalent to increase a fuzzy controller which acts on the self-adjustment factor $\beta$, based on the original basic fuzzy controller.Meanwhile, the PID control parts introduce the integral separated PID control algorithm: Integral action is removed when the control deviation is larger, to avoid the generation of integral saturation; Integral action is reintroductioned when the control deviation is smaller. Not only play an integral role, but also eliminate the static error, both to ensure the control precision to avoid the generation of oscillation. We can make a dynamic tuning for $\Delta \mathrm{Kp}, \Delta \mathrm{Ki}, \Delta \mathrm{Kd}$ by selecting the appropriate fuzzification and defuzzification method according to the table of the fuzzy rules. Suppose $\mathrm{K}_{\mathrm{p} 0}, \mathrm{~K}_{\mathrm{i} 0}, \mathrm{~K}_{\mathrm{d} 0}$ as the initial parameter value of PID controller[3].The parameter calculation formula of the fuzzy PID controller with self-adjustment factor as follows:

$$
K_{p}=K_{p 0}+\Delta K_{p} ; \quad K_{i}=K_{i 0}+\Delta K_{i} ; \quad K_{d}=K_{d 0}+\Delta K_{d} .
$$

The process of the intelligent controller is that: In order to achieve optimal control, seting the parameters of the PID controller according to the value of $e$ and $e c$ and the self-adjustment factor $\beta$ in current system, and considering the interaction from $\mathrm{Kp}, \mathrm{Ki}, \mathrm{Kd}$ work on the system error,as well acording to technical knowledge and practical experience of the engineering staff .

Table 1 Fuzzy controling-rule of $\beta$

\begin{tabular}{|c|c|c|c|c|c|c|c|c|}
\hline \multirow{2}{*}{\multicolumn{2}{|c|}{$\beta$}} & \multicolumn{7}{|l|}{$\mathrm{e}$} \\
\hline & & $\mathrm{NB}$ & NM & $\mathrm{NS}$ & $\mathrm{ZO}$ & PS & PM & PB \\
\hline \multirow{7}{*}{$|\mathrm{ec}|$} & NB & M & $\mathrm{S}$ & S & VS & VB & VB & VB \\
\hline & $\mathrm{NM}$ & M & M & M & S & VB & VB & $\mathrm{VB}$ \\
\hline & $\mathrm{NS}$ & B & B & M & $M$ & $\mathrm{VB}$ & VB & $\mathrm{VB}$ \\
\hline & $\mathrm{ZO}$ & VB & $\mathrm{VB}$ & $B$ & $\mathrm{M}$ & B & VB & $\mathrm{VB}$ \\
\hline & PS & VB & $\mathrm{VB}$ & $\mathrm{VB}$ & M & M & B & B \\
\hline & $\mathrm{PM}$ & VB & VB & VB & $\mathrm{S}$ & $\mathrm{M}$ & M & $\mathrm{M}$ \\
\hline & $\mathrm{PB}$ & VB & VB & VB & VS & $\mathrm{S}$ & $\mathrm{S}$ & M \\
\hline
\end{tabular}

Table 3 Fuzzy controling-rule of $\Delta \mathrm{Ki}$

\begin{tabular}{l|l|l|l|l|l|l|l|l}
\hline \multicolumn{2}{c|}{} & \multicolumn{2}{|c|}{$|\mathrm{e}|$} \\
\cline { 3 - 9 }$\Delta$ Ki & NB & NM & NS & Z0 & PS & PM & PB \\
\hline \multirow{6}{*}{$\mid$ ec $\mid$} & NB & NB & NM & NM & NS & NS & Z0 & Z0 \\
\cline { 2 - 9 } & NM & NM & NM & NS & NS & Z0 & Z0 & Z0 \\
\cline { 2 - 9 } & NS & NM & NM & NS & Z0 & Z0 & Z0 & NS \\
\cline { 2 - 9 } & Z0 & PS & PS & Z0 & Z0 & Z0 & NS & NS \\
\cline { 2 - 9 } & PS & PS & Z0 & Z0 & Z0 & PS & PM & PM \\
\cline { 2 - 9 } & PM & Z0 & Z0 & Z0 & PS & PS & PM & PM \\
\cline { 2 - 9 } & PB & Z0 & Z0 & PS & PS & PM & PM & NB \\
\hline
\end{tabular}

Table 2 Fuzzy controling-rule of $\Delta \mathrm{Kp}$

\begin{tabular}{|c|c|c|c|c|c|c|c|c|}
\hline \multirow{2}{*}{\multicolumn{2}{|c|}{$\Delta \mathrm{Kp}$}} & $\mathrm{e}$ & & & & & & \\
\hline & & $\mathrm{NB}$ & NM & $\mathrm{NS}$ & $\mathrm{ZO}$ & PS & PM & $\mathrm{PB}$ \\
\hline \multirow{7}{*}{ ec } & NB & $\mathrm{PB}$ & $\mathrm{PB}$ & $\mathrm{PB}$ & $\mathrm{PB}$ & PM & PS & $\mathrm{ZO}$ \\
\hline & NM & $\mathrm{PB}$ & PB & $\mathrm{PB}$ & $\mathrm{PB}$ & PM & $\mathrm{ZO}$ & $\mathrm{ZO}$ \\
\hline & $\mathrm{NS}$ & PM & PM & PM & PM & PS & 20 & $\mathrm{NS}$ \\
\hline & $\mathrm{ZO}$ & PM & PS & PS & $Z 0$ & $\mathrm{NS}$ & $\mathrm{NS}$ & NM \\
\hline & PS & PS & $\mathrm{ZO}$ & $\mathrm{NS}$ & $\mathrm{NM}$ & NM & NM & NM \\
\hline & PM & $\mathrm{ZO}$ & $\mathrm{ZO}$ & $\mathrm{NM}$ & $\mathrm{NB}$ & $\mathrm{NB}$ & $\mathrm{NB}$ & $\mathrm{NB}$ \\
\hline & PB & $\mathrm{ZO}$ & $\mathrm{NS}$ & $\mathrm{NM}$ & $\mathrm{NB}$ & NB & $\mathrm{NB}$ & $\mathrm{NB}$ \\
\hline
\end{tabular}

Table 4 Fuzzy controling-rule of $\Delta \mathrm{Kd}$

\begin{tabular}{|c|c|c|c|c|c|c|c|c|}
\hline \multirow{2}{*}{\multicolumn{2}{|c|}{$\Delta \mathrm{Kd}$}} & e & & & & & & \\
\hline & & NB & NM & NS & $\mathrm{ZO}$ & PS & PM & PB \\
\hline \multirow{7}{*}{$|\mathrm{ec}|$} & $\mathrm{NB}$ & PS & $\mathrm{NB}$ & $\mathrm{NB}$ & $\mathrm{NS}$ & $\mathrm{NB}$ & NB & PS \\
\hline & NM & PS & NB & $\mathrm{NB}$ & $\mathrm{NS}$ & $\mathrm{NB}$ & NB & PS \\
\hline & $\mathrm{NS}$ & $\mathrm{ZO}$ & NM & $\mathrm{NM}$ & $\mathrm{NS}$ & $\mathrm{NM}$ & NM & $\mathrm{ZO}$ \\
\hline & 20 & $\mathrm{ZO}$ & NS & $\mathrm{NS}$ & $\mathrm{NS}$ & $\mathrm{NS}$ & $\mathrm{NS}$ & $Z 0$ \\
\hline & PS & $\mathrm{ZO}$ & PM & PS & $Z 0$ & PS & PM & $Z 0$ \\
\hline & PM & PS & PB & PS & PS & PB & PB & PS \\
\hline & PB & PS & PB & PM & PM & PB & PB & PS \\
\hline
\end{tabular}




\section{Simulation and result}

This paper uses the Simulink simulator provided by Matlab7.0 to simulation.During the process of online operation, control system completes the PID parameter online self-tuning by look-up table and operation the results of fuzzy logic rules. Simulation process as follows: Taking $e$ and $e c$ as the input of the fuzzy controller which adjustment $\beta$, Language variable value of $\{\mathrm{NB}, \mathrm{NM}, \mathrm{NS}, \mathrm{ZO}, \mathrm{PS}, \mathrm{PM}$, PB \} seven fuzzy values that represent \{ negative big, negative middle, negative small, zero, positive small, positive middle, positive big\}. The domain of $\beta$ which is the output of the fuzzy control part is $[0,1]$, we can get the domain of each parameter: $\{0,0.1,0.2,0.3,0.4,0.5,0.6,0.7,0.8,0.9,1\}$, and the fuzzy subset: $\{\mathrm{VS}, \mathrm{S}, \mathrm{M}, \mathrm{B}, \mathrm{VB}\}$. Establish the control rules about the self-adjustment factor $\beta$ based on the above analysis about the error and error rate in different circumstances,as shown in Table 1.Selecting $\Delta \mathrm{Kp}, \Delta \mathrm{Ki}, \Delta \mathrm{Kd}$ as the output language variable value of the whole control system, and $\{\mathrm{NB}, \mathrm{NM}, \mathrm{NS}, \mathrm{ZO}, \mathrm{PS}, \mathrm{PM}, \mathrm{PB}\}$ seven fuzzy rules as the output language variable value. Fuzzy theory domain of the input quantity $e$ and $e c$ and Output quantity $\Delta \mathrm{Kp}, \Delta \mathrm{Ki}$, $\Delta \mathrm{Kd}$ all are $\{-3,3\}$. The distribution curve of input and output variables uses trapezoidal membership function. And defuzzification procedure takes the maximum degree of membership in small [4].Respectively make the fuzzy rules for these three parameters $\Delta \mathrm{Kp}, \Delta \mathrm{Ki}, \Delta \mathrm{Kd}$ as shown in Table 2, Table 3 and Table 4.Establish Simulink simulation model according to the fuzzy control rules.Make simulation model of the known proportional valve control system by common fuzzy PID controller and the new intelligent controller proposed in this paper.

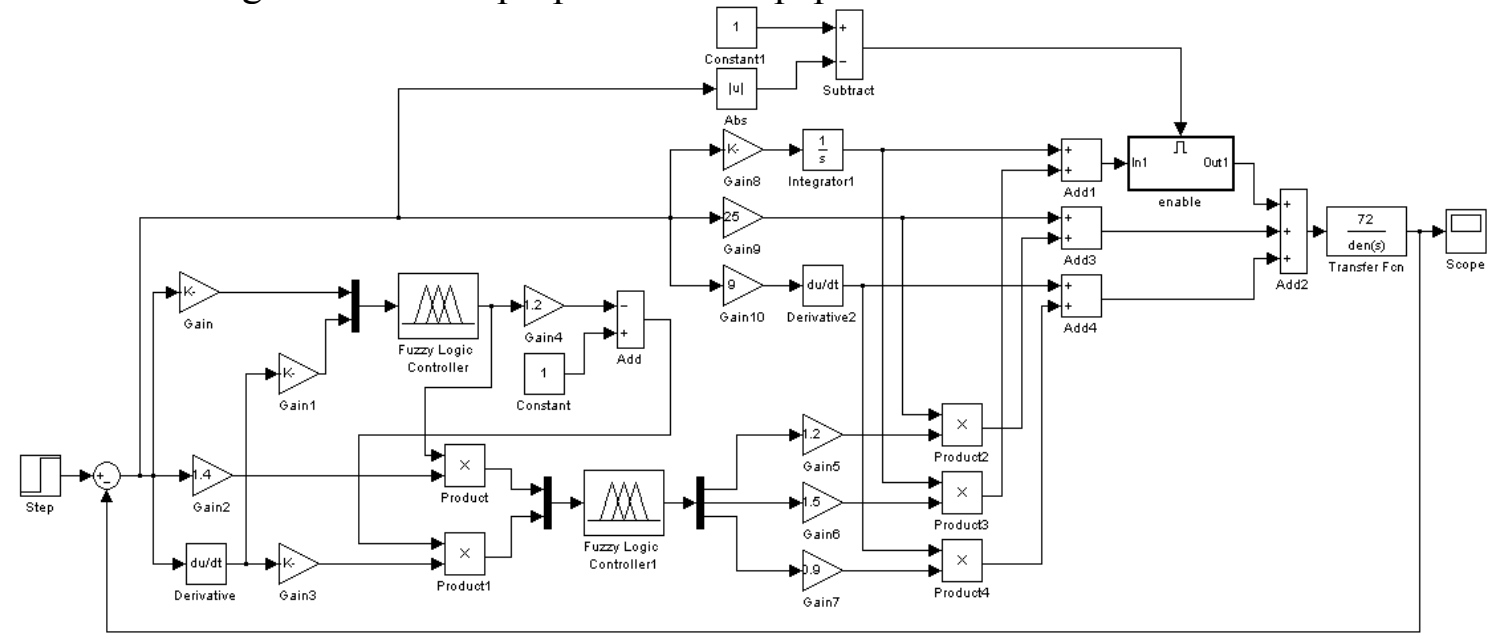

Fig.2, Simulation block diagram from Simulink

Description: Proportional directional valve generally regards as a second-order link in engineering. The transfer function is:

$$
W_{p v}(s)=\frac{K_{q}}{\frac{s^{2}}{\omega_{v}^{2}}+\frac{2 \delta_{v} s}{\omega_{v}}+1}
$$

Where: $\mathrm{Kq}$ is the Flow gain of the proportional valve $\mathrm{m} 3 /(\mathrm{s} \cdot \mathrm{A})$;

$\Omega \mathrm{v}$ is the Phase frequency width of the proportional valve $(\mathrm{rad} / \mathrm{s})$;

$\delta \mathrm{v}$ is the Damping ratio of the proportional valve [5].

According to the controlled object namely proportional valve parameters we can take the corresponding mathematical model:

$$
G(s)=\frac{72}{\mathrm{~s}^{2}+14 \mathrm{~s}+100} .
$$

The input signal of the simulation process is a step signal and the sampling period is $0.1 \mathrm{~s}$, simulation time was $1 \mathrm{~s}$. There are three initial parameter of the PID: $\mathrm{Kp} 0=25, \mathrm{Ki} 0=4.5, \mathrm{Kd} 0=9$, after several debugging. We can get the correction amount of the three parameters of PID according to the 
fuzzy rules.Finally,we can recieve three actual adjustment amount of the intelligent controller after plus the initial value of the integral separated PID parameter. Establishing simulation block diagram in Simulink shown as Figure 2. The results of the control effect are shown as Fig.3 (A) and (B):

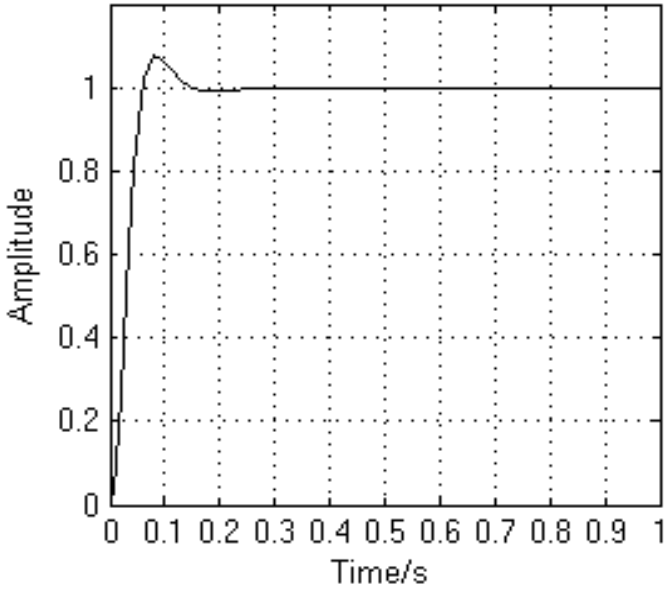

Fig.3 (A)Troditional fuzzy PID controller

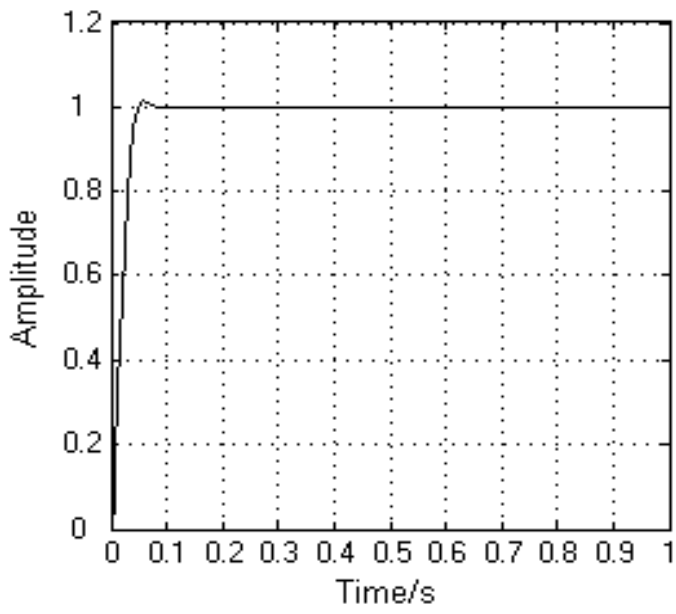

Fig.3 (B) New intelligent controller

As can be seen from the simulation results:(A) system , rise time $\operatorname{tr}=0.075 \mathrm{~s}$, overshoot $\sigma \%=$ $1.07 \%$, adjustment time ts $=0.22 \mathrm{~s} ;(\mathrm{B})$ system , rise time $\operatorname{tr}=0.03 \mathrm{~s}$, overshoot $\sigma \%=1.01 \%$, adjustment time ts $=0.061 \mathrm{~s}$. The contrast can be seen that intelligent controller proposed in this paper has a smaller overshoot, a short adjust time, high controlling accuracy, good stability, and more robustness. The control rules could be changed timely by correcting factor $\beta$ and then using optimized control rules improve the performance of the fuzzy controller. Finally combining with the integral separated PID which has an excellent control effect to improve the performance of the entire control system.

\section{Summary}

The premise of better Fuzzy control effect is that there must be better and reasonable control rules, but the control rules and query tables are designed on the basis of human experience, so it is difficult to have a high and perfect control accuracy because of the inevitably subjective factors. And the effect of fuzzy control will be influenced when the dynamic characteristics of the object changes or influenced by random interference[6]. Therefore the control rules and query table need to be corrected continuously and timely. A new kind of fuzzy PID controller with self-adjustment factor is designed in this paper that could make the PID parameters dynamically changed based on the changes of the erro and the erro rate. This intelligent control method achieves the best control effect of the system by combined traditional fuzzy PID control with the expert system.

\section{References}

[1] X.Y.Liu: Design and research of Fuzzy-PID Controller in Electro-Hydraulic Proportional Valve System. (Guangdong University of Technology,2009.)

[2] X.Yang: Research of control strategy for new type of proportional multiple directional valves used in excavator.(Central South University,2008)

[3] E.T.Zhou, S.X.Liao, D.Mou: Machine Tool \& Hydraulics vol.6(2003),P.225-227

[4] P J.King and E.H.Mamdani: Automatica vol. (2002),P.235 242.

[5] Mudi,Rajani K.Pal,Nikhil R,Robust:IEEE Transactions on Fuzzy Systems vol.7(1999),P.2-16.

[6] Z Q Wu:Fuzzy Sets and Systems vol.47(1992),P.13-21. 